\title{
NPC-Exosome Carry Wild and Mutant-type p53 among Nasopharyngeal Cancer Patients
}

\author{
Hamsu Kadriyan ${ }^{1, *}$, Eka Sunarwidhi Prasedya², Nova Audrey Luetta Pieter ${ }^{3}$, Masyita Gaffar ${ }^{3}$, \\ Amsyar Akil ${ }^{3}$, Agusalim Bukhari ${ }^{4}$, Budu Budu ${ }^{4}$, Andi Alfian Zainuddin ${ }^{4}$, Rina Masadah ${ }^{4}$, \\ Achmad Chusnu Rhomdoni ${ }^{5}$, Abdul Qadar Punagi ${ }^{3}$
${ }^{1}$ Department of Otolaryngology Head and Neck Surgery, Faculty of Medicine, Universitas Mataram, Jl. Majapahit No.62, Mataram, Indonesia ${ }^{2}$ Centre for Bioscience and Biotechnology, Universitas Mataram, Jl. Majapahit No.62, Mataram, Indonesia
${ }^{3}$ Department of Otolaryngology Head and Neck Surgery, Faculty of Medicine, Universitas Hasanuddin, Jl. Perintis Kemerdekaan No.KM.10, Makassar, Indonesia
${ }^{4}$ Postgraduate Program, Faculty of Medicine, Universitas Hasanuddin, J1. Perintis Kemerdekaan No.KM.10, Makassar, Indonesia
${ }^{5}$ Department of Otolaryngology Head and Neck Surgery, Faculty of Medicine, Universitas Airlangga, Jl. Mayjen Prof. Dr. Moestopo No.47, Surabaya, Indonesia
*Corresponding author. E-mail: hamsu@unram.ac.id

Received date: Oct 1, 2021; Revised date: Nov 11, 2021; Accepted date: Nov 15, 2021

\section{Abstract}

$\mathrm{B}$ ACKGROUND: Nasopharyngeal cancer (NPC) is known to release a specific exosome. NPC-derived exosome (NPC-Exo) could carry p53. However, information regarding the type of p53 carrier on NPC-Exo remains limited. This study aims to introduce our important findings regarding the type of p53 NPC-Exo cargo.

METHODS: Serum from patients with NPC were prepared for exosome isolation with Seramir Exoquick by following the manual instructions. RT-PCR was conducted to determine the expression levels of latent membrane protein 1 (LMP-1) and p53 in the exosome isolate. Partial sequencing of p53 amplicon was conducted to determine mutation type of $\mathrm{p} 53$.

\section{Introduction}

Nasopharyngeal cancer (NPC) was one of the commonest head and neck malignancy in Southeast Asia. The global NPC incidence is $1.7 / 100,000$ per year. Estimated incidence of NPC in Indonesia is quite high, which is $8.3 / 100,000$ per year $(1,2)$. On the other hand, the incidence was rare in Europa and America.(3) Histologically, NPC cell dominated by undifferentiated squamous cell carcinoma. $(4,5)$
RESULTS: There were 8 patients enrolled in this study. According to RT-PCR results, the expression levels of LMP-1 and p53 varied in the NPC-Exo isolate. Based on sequencing analysis, 1 case of p53 mutation was noticeable.

CONCLUSION: According to current results, the NPCderived exosome potentially carries not only wild type but also mutant type p53. Further research is needed to explore deeper the effect of the mutant type p53 as an exosome carrier in the clinical application.

KEYWORDS: Nasopharyngeal cancer, exosome, p53, mutation

Indones Biomed J. 2021; 13(4): 403-8
Cancer cells, including NPC, has been known to release a specific exosome. Exosomes are nano-sized vesicles which are enriched with several biomolecules such as protein, DNA, RNA, including p53.(6) The exosome released by the NPC cells is called NPC-derived Exosome (NPC-Exo). (6) Tumor derived exosome was successfully isolated form the serum of NPC patients. In advance, the concentration of circulating exosome was correlated with the lymph node metastasis status.(7) NPC-Exo found to have a role in angiogenesis. The angiogenesis effect was occurs through 
activated the tubulogenesis.(8) NPC-Exo also have a role on promoting tumor progression due to over expression of several miRNAs such as hsa-miR-24-3p, hsa-miR-891a, hsa-miR-106a-5p, hsa-miR-20a-5p, and hsa-miR-1908.(7)

Latent membrane protein 1 (LMP-1) is a major oncogene of Epstein Barr Virus that is known as a major cause of NPC.(9) Indeed, if LMP-1 is found in the exosome, it could suggested that the exosome is released by the NPC. NPC-Exo will circulate to other cells and in its destination will release their biomolecules cargo. The cargo that have been released could affect the physiology of the destination cells, and this will depend on the type of material released.(10)

The $\mathrm{p} 53$ has been well known as a major pro-apoptotic related protein. Wild type p53 (WT-p53) plays an important role in the process of cell cycle arrest, DNA repair, apoptosis, and senescence.(11) However, in cancer, due to mutation, the $\mathrm{p} 53$ could changes to the opposite character. The p53 mutation may lead to the delay of cell program death and induced cancer cell growth. Several studies have reported the type of mutation of p53, mainly in the form of a missense of mutant protein with the complete length $(12,13)$ The mutation of p53 in NPC is rare. Only $39.6 \%$ p53 mutation on NPC patients.(13)

To date, there remains limited studies which have reported the p53 mutation as the NPC-Exo cargo. This is very important for future treatment strategy to treat NPC because exosomes could be modified to incorporate several molecules or proteins such as wild-type p53. Hence, in this study, the authors would like to introduce our important findings regarding the p53 type mutation as an NPC-Exo cargo.

\section{Methods}

\section{Subject Recruitment and Sample Collection}

The subjects were collected in Wahidin Sudirohusodo Hospital and West Nusa Tenggara General Hospital, Indonesia. Characteristics of the patient were collected from the medical records. Ethical clearance was obtained from ethical committee Faculty of Medicine Hasanuddin University no. 53/UN4.6.4.5.31/PP36/2020. The diagnosis was established by the attending physician based on clinical appearance, imaging, and histopathology workup. The staging was established based on tumor primer $(\mathrm{T})$ size, regional lymph node $(\mathrm{N})$, and distant metastasis $(\mathrm{M})$ according to the American Joint Committee on Cancer (AJCC) 2018.(7)

\section{Exosome Isolation}

A serum of the subject was taken from the forearm vein and stored in a $-80^{\circ} \mathrm{C}$ refrigerator until a sufficient number of samples were collected. Isolation of exosome was done with Seramir Exoquick (System Bioscience, Palo Alto, CA, USA) by following the manual instruction.

\section{Real Time Polymerase Chain Reaction (RT-PCR) for LMP-1, p53, and GAPDH}

To validate that the exosome was released by NPC, testing using RT-PCR was conducted by amplification in first step with $94^{\circ} \mathrm{C}$ for 2 minute and continued by 40 cycles for 60 second at $94^{\circ} \mathrm{C}, 45$ minutes at $57^{\circ} \mathrm{C}$ and 60 second at $72^{\circ} \mathrm{C}$. The process continued with $72^{\circ} \mathrm{C}$ for 2 minutes with RotorGene Q 2plex RT-PCR System. SensiFAST SYBR NoROX kit (Thermofisher Scientific, Waltham, MA, USA) was done to check whether there was an expression of LMP-1 or not inside the exosomes. The primer for LMP1 consists of forward 5'-CAGTCAGGCAAGCCTATGA-3' and reverse 5'-CTGGTTCCGGTGGAGATGA-3'.(14) Glyceraldehide-3-phospate dehydrogenase (GAPDH) was used as a positive control in this study. If the exosome has been validated and was confirmed to be released by NPC, an advance RT-PCR with the similar procedure on LMP-1 was done to check whether the NPC-Exo carries the p53 or not. Authors choose the exon 4-6 due to its frequent location of mutation. $(13,15)$ The primer for $\mathrm{p} 53$ consists of 2 different primers on exon 4-5 and 5-6 sequentially as follows forward and reverse 5'-GCCATCTACAAGCAGTCACAG-3' and 5'-TCATCCAAATACTCCACACGC-3', 5'-GAAGGAAATTTGCGTGTGGAG-3' and 5'-AGTGTGATGATGGTGAGGATG-3'. The primers were designed with Primer3plus.(16) The primers were further validated and purchased from Integrated DNA Technologies-IDT (Coralville, IA, USA). The expression of LMP-1, p53, and GAPDH by RT-PCR was determined by the measurable number of PCR cycles from where the fluorescence signal crosses the base (threshold) line.

\section{Sequencing Analysis}

If the expression of p53 occurs, the sequencing will be done to explore the type of p53 was wild or mutant type. Sequencing examination was sent to $1^{\text {st }}$ Base (Selangor, Malaysia) by sending the RT-PCR product. The sequence result was then read with Sequence Scanner 2.0 software (Thermofisher Scientific) and continued by BioEdit ${ }^{\mathrm{TM}}$ ( Informer Technologies, Los Angles, CA, USA) to edit the alignment. The result was then uploaded to NCBI for BLAST, and to be compared with gene bank. 
Table 1. Characteristics of the subjects.

\begin{tabular}{ccccc}
\hline Subject No. & Age (Years) & Gender & Stage & Histopathology \\
\hline 1 & 37 & $\mathrm{~L}$ & 3 & Undifferentiated SCC \\
2 & 54 & $\mathrm{P}$ & 3 & Undifferentiated SCC \\
3 & 36 & $\mathrm{~L}$ & 3 & Undifferentiated SCC \\
4 & 42 & $\mathrm{~L}$ & 3 & Undifferentiated SCC \\
5 & 23 & $\mathrm{~L}$ & 3 & Moderated differentiated SCC \\
6 & 28 & $\mathrm{P}$ & 3 & Undifferentiated SCC \\
7 & 47 & $\mathrm{~L}$ & 3 & Undifferentiated SCC \\
8 & 49 & $\mathrm{~L}$ & $4 \mathrm{~A}$ & Undifferentiated SCC \\
\hline \multicolumn{5}{c}{ Mean=39.5 } \\
\hline
\end{tabular}

\section{Results}

Eight subjects were enrolled on this study, most of them were male under 50 years old. The subject were mostly at stage 3 and there were no subjects on stages 1 and 2. Based on the histopathology, the majority had undifferentiated squamous cell carcinoma (SCC), none of them is welldifferentiated SCC (Table 1).

\section{Expression of LMP-1}

All exosomes that isolated from the NPC subjects were express the LMP-1. The CT value expression was ranged between 32.60-38.13 with a mean of 35.02. The detailed CT value expression of LMP-1 in the exosome is seen in Table 2. The housekeeping gene (GAPDH) are also expressed with mean $\mathrm{CT}$ value 28.43 .

\section{Expression of p53}

The expression of p53 either on exon 4-5 and 5-6 are expressed with the range of CT value 25.42-28.03 and 28.38-31.67 with the mean 26.87 and 30.24 , consecutively. The detailed result was shown in Table 2.

\section{Sequencing Result for p53}

The base-pair pattern for $\mathrm{p} 53$ in all subjects were expressed well on sequencing analysis. We found 1 (12.5\%) mutant type of p53 in this study. The base pair pattern as shown in chromatogram Figure 1 (subject no. 6). The BLAST analysis result for subject no. 6 is shown in Figure 2. The BLAST analysis for other subjects is found similar to the database on gene bank. According to 3 consecutive sequencing and BLAST analysis, the mutation is consistence found in codon 180. As a result, GAG represent the glutamic acid, changes to GGA represent the glycine.

\section{Discussion}

Previous study has demonstrated that exosome released by NPC cells could contain LMP-1.(17) This study found that all exosome isolate expressed the LMP-1 on the RT-PCR. Exosome from the tumor could be found either in the tumor cells or body liquid, including blood serum.(18) Therefore, the exosome isolated in this study is suggested NPC-Exo.

The most common mutations in the tumor suppressor gene p53 occurred at codon 173, located in exon 5. It occurs

Table 2. The CT value expression of LMP-1, p53, and GAPDH on NPC-Exo cargo.

\begin{tabular}{ccccc}
\hline Subject No. & LMP-1 & P53 Exon 4-5 & P53 Exon 5-6 & GAPDH \\
\hline 1 & 32.60 & 26.19 & 29.64 & 26.94 \\
2 & 34.12 & 27.1 & 30.71 & 29.00 \\
3 & 38.13 & 26.27 & 28.38 & 25.25 \\
4 & 35.36 & 28.38 & 29.98 & 30.82 \\
5 & 33.76 & 26.68 & 30.28 & 31.82 \\
6 & 36.73 & 25.42 & 31.17 & 23.15 \\
7 & 33.21 & 26.91 & 30.06 & 28.34 \\
8 & 36.25 & 28.03 & 31.67 & 32.15 \\
\hline Mean & 35.02 & 26.87 & 30.24 & 28.43 \\
\hline
\end{tabular}




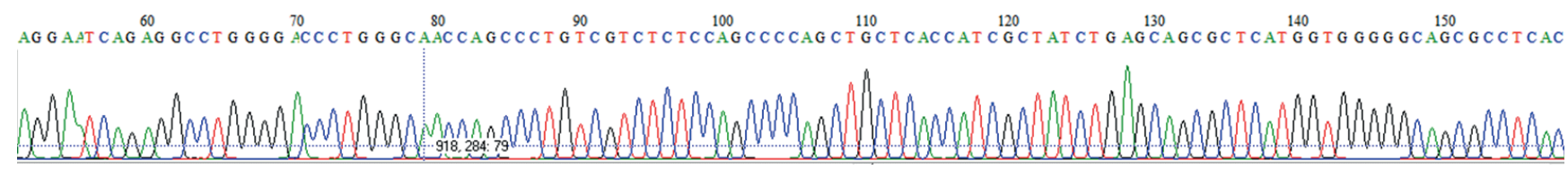

Figure 1. The chromatogram of sequencing base-pair pattern of p53 as exosome cargo.

in $26 \%$ of 207 NPC patients.(13) Another study showed that p53 has a positive association with low survival rates, but this study did not identify whether the expression was the wild or mutant type. However, according to the researcher, p53 mutant type is more stable and has a longer life span compared to wild types. According to that facts, the researcher suggested that they found the mutant type, even though did not do an in-depth examination for it.(19)

The most type of p53 mutation is missense, whereas the non-sense mutation only occurs in $10 \%$ of cases.(20) Following the missense, frameshift was also common on the p53 mutation.(13) According to the current study, comparation of p53 sequencing in exosomes cargo to the IARC database (21) showed that there was a difference of a base which was the insertion of the $\mathrm{G}$ base.

The insertion of $\mathrm{G}$ base on exon 5 on codon 180 may allowed the changes of base sequence from GAG to $(\mathrm{G})$ GAG. GAG sequence will produce a glutamic acid, on the other hand, GGA will produce glycine according to standard genetic code. The changes in amino acid production will lead to missense and could promote the changes of the p53 character. The type of this mutation is a novel finding which can be use as one of the indicator to follow the NPC progress. However, further research is needed to prove this finding.

The p53 mutation on NPC could appear in exon 2-9. There were several types of mutation such as deletion, duplication, and multiple duplication. Study in Hongkong and Guangxi mainly found the mutation on exon 5.(15) In exon 5, mutations from GTG nucleotides to ATG can occur which result in changes in the protein production (missense).(13) Mutations in exon 5 can occur at codons $173,175,176$, and 177. In exon 6 mutations can occur at codon 196.(15) In exon 7, mutations can occur in codon 242, 249, and 261.(13) In exon 8, there can be mutations at codon 280 from AGA to ACA in NPC cell lines that can increase NPC oncogenicity.(22)

Mutant p53 was associated with the poor prognosis in colon cancer. This condition was related to macrophage reprogramming through the exosomal miR-1246.(23) Furthermore, determination of p53 type in NPC-Exo is very important. p53 could be transferred through exosomes between the cells.(10) It is also reported that exosome could carry drugs such as curcumin, paclitaxel, and doxorubicin as an anti-cancer agent. In addition, exosomes could carry microRNA-155 that can suppress the cancer growth with the

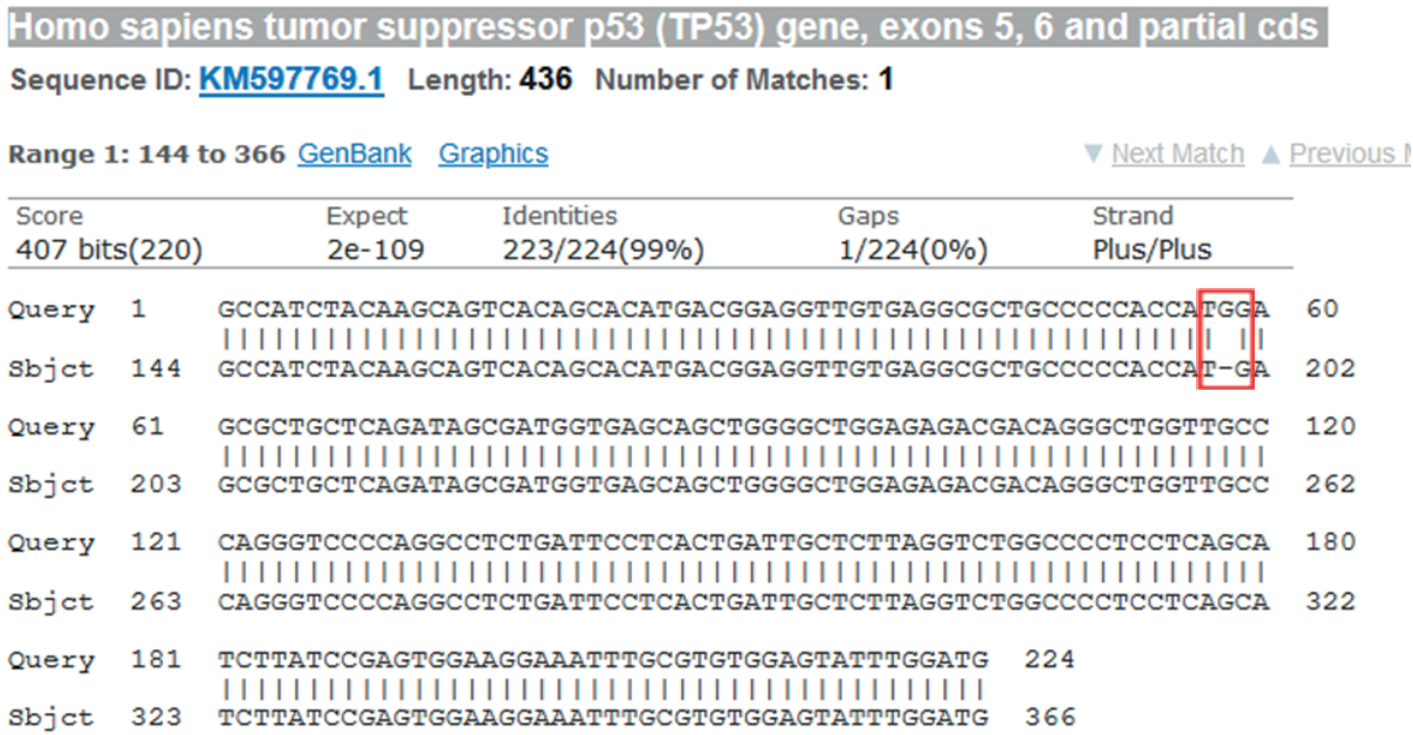

Figure 2. BLAST analysis of the RT-PCR product of p53 on exon 5-6 indicated a gap (insertion of G base) on the sequencing (red box). 
minimal side effects.(24) Previous study has successfully inserted wild type p53 and microRNA125b to the tumor exosome.(25) This result could increase the possibility of this method as one of the choice to increase the treatment result on NPC patients.

Wild-type p53 use the exosome as a messenger to communicate with the other cell to controlled cancer growth and to prevent the metastasis.(26) Furthermore, aside from treatment impact, the clinical application of wild-type p53 insertion on exosomes will affect the prognosis of the case.

The other function of exosome was used as a biomarker to monitoring the effectiveness of treatment in cancer management.(27) Several studies showed that exosome has a role on non-interventional diagnosis marker and to predict the prognosis.(6) The p53 content in exosomes derived from brain glioblastoma cancer cells, both from tumors and blood, showed equal expression. This indicates that p53 in exosomes taken from blood has the potential to be used as a marker in the non-interventional diagnosis of brain glioblastoma cancer.(28) With the current results, there is an opportunity to develop these findings into diagnostic biomarkers in NPC.

Based on the evidence above, with the increase of research in this field, nanovesicles such as exosomes will play an important role either on diagnosis, treatment, and prognosis follow-up. However, its clinical application may need more massive studies to make this purpose realize. In this study, there were several limitations. The sample size was small, found only 1 mutation out of 8 subjects, and did not explore this mutation effect to the NPC case. Finally, further research should be done to overcome the limitation.

\section{Conclusion}

NPC-derived exosomes potentially carry not only wild-type but also mutant type $\mathrm{p} 53$. This finding is very important for the future strategy on management of NPC with exosome. Further research is needed to gain more understanding of the effect of the exosome mutation cargo in the clinical application.

\section{Acknowledgements}

Authors thanks Mrs Suly Ulhie (research center Hasanuddin University Hospital) and dr. Foppy (Otolaryngology resident Hasanuddin University) for their assistance on collecting the sample.

\section{Authors Contribution}

HK, NALP, MG, AQP concept the study and developed the manuscript; HK, ESP performed the laboratory testing; $\mathrm{AB}, \mathrm{BB}, \mathrm{AAZ}, \mathrm{RM}, \mathrm{ACR}$ critical review the manuscript; all authors were read and agree with the final manuscript.

\section{References}

1. Kurniawan A, Risanti ED, Suhda S, Rinonce HT, Dwianingsih EK, Fachiroh J. Wnt inhibitory factor 1 (WIF1) qualitative-methylation from peripheral blood could not be used as biomarker for the risk of nasopharyngeal carcinoma or smoking behavior in yogyakarta panel. Indones Biomed J. 2019; 11: 273-8

2. Risanti ED, Kurniawan A, Wahyuningsih L, Dwianingsih EK, Rinonce HT, Fachiroh J. Association of peripheral blood RASSF1A and CDKN2A methylation status with smoking behaviour in nasopharyngeal carcinoma. Indones Biomed J. 2018; 10: 123-7.

3. Shield KD, Ferlay J, Jemal A, Sankaranarayanan R. The global incidence of lip, oral cavity, and pharyngeal cancers by subsite in 2012. CA Cancer J Clin. 2017; 67: 51-64.

4. Adham M, Kurniawan AN, Muhtadi AI, Roezin A, Hermani B, Gondhowiardjo S, et al. Nasopharyngeal carcinoma in Indonesia: epidemiology, Incidence, sign, and symptoms at presentation. Chin J Cancer. 2012; 31: 185-96.

5. Kuhuwael FG, Perkasa MF, Miskad UA, Punagi AQ, Said FA. Comparison of the means of argyrophilic nucleolar organizer region (mAgNOR) pre- and post-therapy in nasopharyngeal carcinoma patients at Wahidin Sudirohusodo General Hospital Makassar. Indones Biomed J. 2016; 8: 103-8.

6. Zhou Y, Xia L, Lin J, Wang H, Oyang L, Tan S, et al. Exosomes in nasopharyngeal carcinoma. J Cancer. 2018; 9: 767-77.

7. Ye S, Li ZL, Luo D, Huang B, Chen YS, Zhang X, et al. Tumorderived exosomes promote tumor progression and T-cell dysfunction through the regulation of enriched exosomal microRNAs in human nasopharyngeal carcinoma. Oncotarget. 2014; 5: 5439-52.

8. Chan YK, Zhang H, Liu P, Tsao SW, Lung ML, Mak NK, et al. Proteomic analysis of exosomes from nasopharyngeal carcinoma cell identifies intercellular transfer of angiogenic proteins. Int $\mathrm{J}$ Cancer. 2015; 137: 1830-41.

9. Kadriyan H, Yudhanto D, Djannah F, Aryani IGAT, Sulaksana MA. Correlation of cancer stage with expression of LMP-1 and BCL-2 in patients with undifferentiated nasopharyngeal cancer. ASM Sci J. 2021; 14: 33-8.

10. Burdakov VS, Kovalev RA, Pantina RA, Varfolomeeva EY, Makarov EM, Filatov MV. Exosomes transfer p53 between cells and can suppress growth and proliferation of $\mathrm{p} 53$-negative cells. Cell Tissue Biol. 2018; 12: 20-6.

11. Liu J, Zhang C, Hu W, Feng Z. Tumor suppressor p53 and metabolism. J Mol Cell Biol. 2019; 11: 284-92.

12. Sigal A, Rotter V. Oncogenic mutations of the $\mathrm{p} 53$ tumor suppressor: the demons of the guardian of the genome. Cancer Res. 2000; 60: 6788-93.

13. Liu J, Liu Y, Zhang Z, Sun H, Ji X, Li B, et al. Prognostic value of the Epstein-Barr virus and tumor suppressor gene p53 gene in nasopharyngeal squamous cell carcinoma. J Cancer Res Ther. 2019; 15: 426-36. 
14. Zihlif MA, Mahmoud IS, Ghanim MT, Zreikat MS, Alrabadi N, Imraish $\mathrm{A}$, et al. Thymoquinone efficiently inhibits the survival of EBV-infected B cells and alters EBV gene expression. Integr Cancer Ther. 2013; 12: 257-63.

15. Chakrani F, Armand JP, Lenoir G, Ju LY, Liang JP, May E, et al. Mutations clustered in exon 5 of the p53 gene in primary nasopharyngeal carcinomas from Southeastern Asia. Int J Cancer. 1995; 61: 316-20.

16. Untergasser A, Cutcutache I, Koressaar T, Ye J, Faircloth BC, Remm M, et al. Primer3-new capabilities and interfaces. Nucleic Acids Res. 2012; 40: e115. doi: 10.1093/nar/gks596.

17. Keryer-Bibens C, Pioche-Durieu C, Villemant C, Souquère S, Nishi N, Hirashima M, et al. Exosomes released by EBV-infected nasopharyngeal carcinoma cells convey the viral Latent Membrane Protein 1 and the immunomodulatory protein galectin 9. BMC Cancer. 2006; 6: 283. doi: 10.1186/1471-2407-6-283.

18. Li M, Zeringer E, Barta T, Schageman J, Cheng A, Vlassov AV, et al. Analysis of the RNA content of the exosomes derived from blood serum and urine and its potential as biomarkers. Philosopical Trans R Soc B. 2014; 369: 20130502. doi: 10.1098/rstb.2013.0502.

19. Zhang P, Wu SK, Wang Y, Fan ZX, Li CR, Feng M, et al. p53, MDM2, eIF4E and EGFR expression in nasopharyngeal carcinoma and their correlation with clinicopathological characteristics and prognosis: A retrospective study. Oncol Lett. 2015; 9: 113-8.

20. Martin ACR, Facchiano AM, Cuff AL, Hernandez-Boussard T, Olivier M, Hainaut P, et al. Integrating mutation data and structural analysis of the TP53 tumor-suppressor protein. Hum Mutat. 2002; 19: 149-64.

21. Olivier M, Eeles R, Hollstein M, Khan MA, Harris CC, Hainaut P. The IARC TP53 database: New online mutation analysis and recommendations to users. Hum Mutat. 2002; 19: 607-14.

22. Qin ZQ, Li QG, Yi H, Lu SS, Huang W, Rong ZX, et al. Heterozygous p53-R280T mutation enhances the oncogenicity of NPC cells through activating PI3K-Akt signaling pathway. Front Oncol. 2020;10: 104. doi: 10.3389/fonc.2020.00104.

23. Cooks T, Pateras IS, Jenkins LM, Patel KM, Robles AI, Morris J, et al. Mutant p53 cancers reprogram macrophages to tumor supporting macrophages via exosomal miR-1246. Nat Commun. 2018; 9: 771. doi: 10.1038/s41467-018-03224-w.

24. Ren J, He W, Zheng L, Duan H. From structures to functions: Insights into exosomes as promising drug delivery vehicles. Biomater Sci. 2016; 4: 910-21.

25. Trivedi M, Talekar M, Shah P, Ouyang Q, Amiji M. Modification of tumor cell exosome content by transfection with wt-p53 and microRNA-125b expressing plasmid DNA and its effect on macrophage polarization. Oncogenesis. 2016; 5: e250-12.

26. Pavlakis E, Neumann M, Stiewe T. Extracellular vesicles : messengers of p53 in tumor - stroma communication and cancer metastasis. Int J Mol Sci. 2020; 21: 9648. doi: 10.3390/ijms21249648.

27. König L, Kasimir-Bauer S, Bittner AK, Hoffmann O, Wagner B, Santos Manvailer LF, et al. Elevated levels of extracellular vesicles are associated with therapy failure and disease progression in breast cancer patients undergoing neoadjuvant chemotherapy. Oncoimmunology. 2018; 7: e1376153. doi: 10.1080/2162402X.2017.1376153.

28. Yang JK, Song J, Huo HR, Zhao YL, Zhang GY, Zhao ZM, et al. DNM3, p65 and p53 from exosomes represent potential clinical diagnosis markers for glioblastoma multiforme. Ther Adv Med Oncol. 2017; 9: 741-54. 